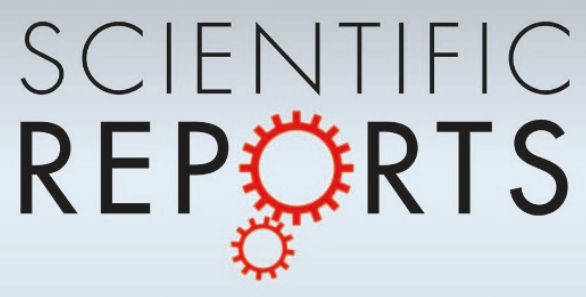

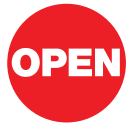

SUBJECT AREAS:

NANOPARTICLES

KINETICS AND DYNAMICS

CHARACTERIZATION AND

ANALYTICAL

TECHNIQUES

SYNTHESIS AND PROCESSING

Received

3 January 2013

Accepted

1 March 2013

Published

21 March 2013

Correspondence and requests for materials should be addressed to

B.Y.Z. (byzhao@sjtu.

edu.cn); J.W.Z.

(jwzheng@suda.edu.

cn) or T.X.F. (txfan@

sjtu.edu.cn)

* These authors contributed equally to this work.

\section{Green "planting" nanostructured single crystal silver}

\author{
Hong Zhao ${ }^{13 *}$, Fei Wang ${ }^{2}$, Yuesheng Ning ${ }^{2 *}$, Binyuan Zhao ${ }^{2,3}$, Fujun Yin ${ }^{3}$, Yijian Lai ${ }^{2}$, Junwei Zheng', \\ Xiaobin $\mathrm{Hu}^{2}$, Tongxiang Fan ${ }^{2}$, Jianguo Tang ${ }^{4}$, Di Zhang ${ }^{2} \& \mathrm{Keao} \mathrm{Hu}^{2}$
}

${ }^{1}$ College of Chemistry, Chemical Engineering and Materials Science, Soochow University, Suzhou, 215123, P. R. China, ${ }^{2}$ State Key Laboratory of Metal Matrix Composites, School of Materials Science and Engineering, Shanghai Jiao Tong University, Shanghai, 200240, P. R. China, ${ }^{3}$ Huaihai Institute of Technology, Jiangsu Marine Resources Development Research Institute, Lianyungang 222005, P. R. China, ${ }^{4}$ College of Chemistry, Chemical and Environmental Engineering, Qingdao University, Qingdao, 266071, P. R. China.

Design and fabrication of noble metal nanocrystals have attracted much attention due to their wide applications in catalysis, optical detection and biomedicine. However, it still remains a challenge to scale-up the production in a high-quality, low-cost and eco-friendly way. Here we show that single crystalline silver nanobelts grow abundantly on the surface of biomass-derived monolithic activated carbon (MAC), using $\left[\mathrm{Ag}\left(\mathrm{NH}_{3}\right)_{2}\right] \mathrm{NO}_{3}$ aqueous solution only. By varying the $\left[\mathrm{Ag}\left(\mathrm{NH}_{3}\right)_{2}\right] \mathrm{NO}_{3}$ concentration, silver nanoplates or nanoflowers can also be selectively obtained. The silver growth was illustrated using a galvanic-cell mechanism. The lowering of cell potential via using $\left[\mathrm{Ag}\left(\mathrm{NH}_{3}\right)_{2}\right]^{+}$precursor, together with the $\mathrm{AgCl}$ crystalline seed initiation, and the releasing of $\mathrm{OH}^{-}$in the reaction process, create a stable environment for the self-compensatory growth of silver nanocrystals. Our work revealed the great versatility of a new type of template-directed galvanic-cell reaction for the controlled growth of noble metal nanocrystals.

 he past decade has witnessed the burgeoning research interest in the controlled synthesis of monodispersed noble metal nanocrystals ${ }^{1-4}$. Various nanostructures such as nanocubes ${ }^{5}$, Nanocages ${ }^{6}$, Nanoplates ${ }^{7}$, nanowires $^{8}$ and nanobelts ${ }^{9}$ have been fabricated. Solution-phase methods involved the reduction of metal ions, and the growth of nanocrystals in aqueous or non-aqueous solution. They were believed to be more adaptive than gas-phase methods in preparing nanostructures with a range of morphologies in bulk quantities ${ }^{10}$. The main solution-phase methods can be categorized to (1) chemical synthesis with or without seed and light mediation, where various types of reductants and capping reagents were often utilized, and (2) hard or soft template-directed growth ${ }^{11}$. In the hard-template approach, a porous anodic aluminum oxide (AAO) membrane often served as the substrate. Since the growth of noble metals was initiated from the bottom of the channels, the synthesized product often had only one-dimensional (nanotubes, nanowires, nanorods and nanobelts etc.) morphology, and the width was confined by the size of the insulating nanochannels. The dissolution of the template with corrosive reagents also lowered the efficiency of this method. There has been very few works on the scaled production of metal nanocrystals with various morphologies using solid template ${ }^{12}$.

In our previous work ${ }^{13}$, silver nanodendrites were prepared on the outer surface of monolithic activated carbon (MAC), by simply immersing MAC into $\mathrm{AgNO}_{3}$ solution. A galvanic-cell mechanism was proposed. In this reaction mechanism (Fig. 1), there are numerous short-circuited nanobatteries composed of reductive groups on the inner surface of the microporous carbon acting as the anode, the growing silver as the cathode, and the conductive carbon skeleton as the external circuit. Considering the large BET surface of activated carbons associated with abundant functional groups, the growth capacity of this method would be quite high. However, in the previous work, only $\mathrm{AgNO}_{3}$ was used as the Ag precursor. The relatively high standard reduction potential of $\mathrm{Ag}^{+} \mid \mathrm{Ag}(0.80 \mathrm{~V})$ produced a high driving force, leading to the kinetically-controlled deposition of silver in a non-equilibrium condition. This could explain why in our previous work, only dendritic silver was obtained $^{14}$. In the current work, a silver complex $\left[\mathrm{Ag}\left(\mathrm{NH}_{3}\right)_{2}\right]^{+}$was used as the silver precursor instead. The lowered reduction potential $\left.\left.\left(\mathrm{E}_{\left(\left[\mathrm{Ag}\left(\mathrm{NH}_{3}\right)_{2}\right]\right.}\right]^{+} / \mathrm{Ag}\right)=0.38 \mathrm{~V}\right)$ greatly improved the controllability of this synthetic approach. Silver nanobelts with well-defined morphology can be routinely prepared. By varying $\left[\mathrm{Ag}\left(\mathrm{NH}_{3}\right)_{2}\right]^{+}$ concentration, the reduction potential can be finely adjusted, leading to the selective growth of nanoplates or nanoflowers. Moreover, it was suggested from our experiments that $\mathrm{OH}^{-}$set free from $\left[\mathrm{Ag}\left(\mathrm{NH}_{3}\right)_{2}\right]^{+}$hydrolysis could help regenerate reductive groups, resume the growth capability of MAC, and sustain the production of 


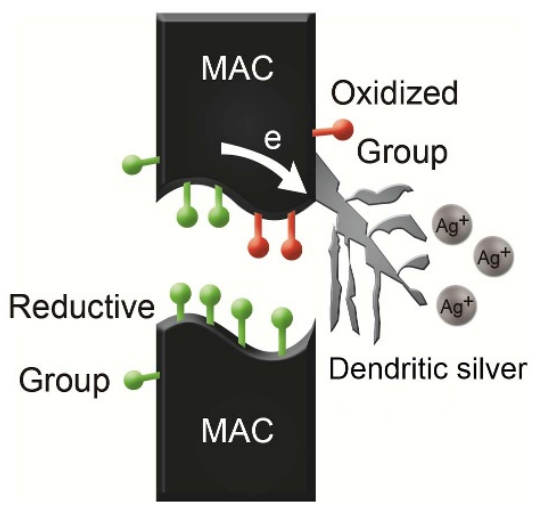

Figure $1 \mid$ A schematic illustrating the formation of nanodendritic Silver. A galvanic cell formed between reductive groups on the inner surface of pores and silver nanoparticles on MAC's outer surface.

silver nanocrystals in a self-compensatory manner. Furthermore, the as-prepared silver nanocrystals can be easily detached from the porous carbon template since they mainly grew on the outer surface, and the MAC can be reactivated by simple post-treatment. Our method may represent a very promising template-directed method to scaling up the production of noble metal nanocrystals with controlled morphology.

\section{Results}

Figure 2a-c display three photographic snapshots of Ag samples growing on MAC at different time, upon immersing two pieces of small MAC (All structural parameters and elemental composition are presented in Supplementary Table S1 and S2 online) in [Ag $\left.\left(\mathrm{NH}_{3}\right)_{2}\right] \mathrm{NO}_{3}$ aqueous solution with $5 \mathrm{mM}$ concentration. (More experimental details are given in the Methods) In about $30 \mathrm{~min}$, shiny Ag crystals quickly grew out of the black MAC (Fig. 2b). Soon after that, fluffy product appeared and its apparent volume became much larger than original MAC after $24 \mathrm{hr}$ (Fig. 2c). SEM image (Fig. 2d) shows wire-like morphology of the fluffy products. The close-up SEM observation (Fig. 2e) clearly shows the belt-like structure, whose typical width is about $1.09 \mu \mathrm{m}$ and typical thickness $0.29 \mu \mathrm{m}$ (the actual width and thickness should be larger due to the tilting of the belt toward the substrate). To study the crystallographic orientation, selected-area-electron-diffraction (SAED, inset in Fig. 2f) was taken near the tip of a silver belt, since the central part of our silver nanobelt is too thick for electron transmitting. The
SAED pattern has a 6-fold symmetry and the $d$ spacing of the planes nearest to the central spot is measured to be $1.44 \AA$, which can be assigned to the $\{220\}$ reflections in a face-centered-cubic (fcc) silver whose (111) surface is perpendicular to the electron beam in TEM observation $^{15}$. Therefore, the photograph and EM images demonstrate that belt-like single crystal silver can be prepared in a high yield (silver product weighed ca. $9 \%$ of MAC) by simply immersing MAC in $\left[\mathrm{Ag}\left(\mathrm{NH}_{3}\right)_{2}\right] \mathrm{NO}_{3}$ aqueous solution.

In addition, the morphology of single crystal silver can be controlled by varying $\left[\mathrm{Ag}\left(\mathrm{NH}_{3}\right)_{2}\right] \mathrm{NO}_{3}$ concentration. Figure 3 shows SEM images of the products obtained by immersing MAC in $\left[\mathrm{Ag}\left(\mathrm{NH}_{3}\right)_{2}\right] \mathrm{NO}_{3}$ solutions at (a) $100 \mathrm{mM}$, (b) $5 \mathrm{mM}$, and (c) $0.1 \mathrm{mM}$ for $24 \mathrm{hr}$. The products obtained at $5 \mathrm{mM}$ (Fig. 3b) consisted of highly pure nanobelts, similar to that mentioned in Fig. 2. At higher concentrations (Fig. 3a), many flower-like products were obtained, in the form of the aggregation of irregular silver nanoplates. On the other hand, at lower concentrations (Fig. 3c), well-crystallized hexagonal silver nanoplates grew on the MAC surface. The change of silver morphology with varying $\left[\mathrm{Ag}\left(\mathrm{NH}_{3}\right)_{2}\right] \mathrm{NO}_{3}$ concentration was also found on other MACs (for another example, see Supplementary Fig. S1 online).

Interestingly, the MAC can be used to grow silver nanocrystals many times, with only simple post-treatment in between. Figure 4 shows that the reactivated MAC can be used to grow almost the same amount of silver samples (compare Figs. $4 \mathrm{~b}$ and $4 \mathrm{e}$ ) as the virgin MAC. The reactivation was performed by taking away the Ag product (Fig. 4c) by tweezers, ultrasonicating the MAC in ammonium solution ( $5 \mathrm{wt} \%$ ) for ca. $1 \mathrm{hr}$, washing with deionized water and drying it at $60^{\circ} \mathrm{C}$ for $2 \mathrm{hr}$ (Fig. $4 \mathrm{~d}$ ). It was found that the ultrasonication can also be carried out in ethanol, or even just deionized water.

To receive hints as to the underlying growth mechanism of silver nanobelts, the surface deposits on the MAC immersed in $5 \mathrm{mM}$ $\left[\mathrm{Ag}\left(\mathrm{NH}_{3}\right)_{2}\right] \mathrm{NO}_{3}$ solution at earlier stages were examined using SEM and XRD (Fig. 5). The black MAC quickly turned gray-yellow after immersing in the solution for ca. 1 min. SEM images (Fig. 5a) reveal that many small cubes and some right bipyramids appeared on the surface, and the corresponding XRD spectrum (Fig. 5 lower panel, curve a) indicates that they are a mixture of $\mathrm{AgCl}$ and $\mathrm{Ag}$. $\mathrm{AgCl}$ is the dominant phase and $\mathrm{Ag}$ the minor. The cubes could be associated with fcc $\mathrm{AgCl}$ phase ${ }^{16}$. After $10 \mathrm{~min}$ (Fig. 5b), the cubes almost disappeared and some hexagonal plates appeared, together with some defected pyramids and irregular structures. The corresponding XRD spectrum (curve $b$ ) indicates that the products are mainly fcc Ag crystals. The basal face of these hexagons can be ascribed to $\{111\}$ plane and the sides to $\{100\}$ planes of fcc $\mathrm{Ag}^{17}$.
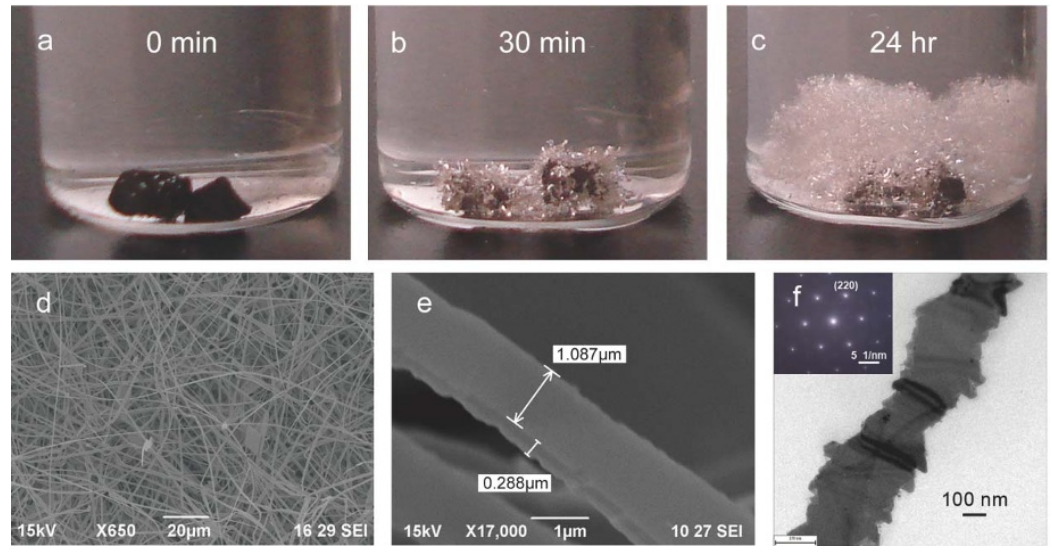

Figure $2 \mid$ Ag nanobelts growing on the monolithic activated carbon (MAC). (a) Photograph for two $\mathrm{MAC}$ pieces just being put in $\left[\mathrm{Ag}\left(\mathrm{NH}_{3}\right)_{2}\right] \mathrm{NO}_{3}$ solution (5 mM); (b) Photograph taken 30 min after MAC pieces being put in $\left[\mathrm{Ag}\left(\mathrm{NH}_{3}\right)_{2}\right] \mathrm{NO}_{3}$ solution $(5 \mathrm{mM})$; (c) Photograph taken $24 \mathrm{hr}$ after MAC pieces being put in $\left[\mathrm{Ag}\left(\mathrm{NH}_{3}\right)_{2}\right] \mathrm{NO}_{3}$ solution $(5 \mathrm{mM})$; (d-e) SEM images of Ag products taken from sample (c) with (d)-low and (e)-high magnification; (f) TEM image near the tip of a Ag nanobelt, together with its selected-area-electron-diffraction (SAED) pattern (shown as the inset). 

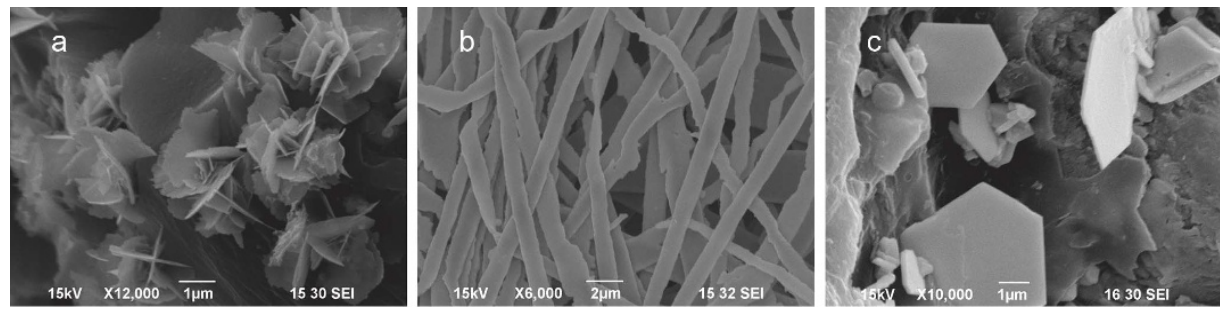

Figure 3 SEM images of Ag samples obtained on monolithic activated carbon (MAC) after being immersed in $\left[\mathrm{Ag}\left(\mathrm{NH}_{3}\right)_{2}\right] \mathrm{NO}_{3}$ solution at different concentrations for $24 \mathrm{hr}$. (a) $100 \mathrm{mM}$; (b) $5 \mathrm{mM}$; (c) $0.1 \mathrm{mM}$. SEM samples for (a) and (c) were MAC surfaces after the growth of Ag products, while sample (b) was Ag product detached from MAC.

The concomitant loss of cubes in SEM (Fig. $4 \mathrm{~b}$ ) and $\mathrm{AgCl}$ phase in $\mathrm{XRD}$ (curve b) suggested that the initially crystallized AgCl cubes underwent reduction and transformed into Ag hexagonal plates, releasing $\mathrm{Cl}^{-}$ions.

It should be mentioned that the $\mathrm{Cl}^{-}$ions for the formation of $\mathrm{AgCl}$ in the first step (Fig. 5a) were inherent in our MAC samples. The content of the $\mathrm{Cl}^{-}$in MAC should be kept at a relatively low level (preferably less than 0.2 at $\%$ as revealed by our XPS results in Supplementary Table S2). It is deduced that $\mathrm{Ag}^{+}$released from $\left[\mathrm{Ag}\left(\mathrm{NH}_{3}\right)_{2}\right]^{+}$first complexed with $\mathrm{Cl}^{-}$ions on MAC, forming $\mathrm{AgCl}$ cubes on the surface. Then, the $\mathrm{AgCl}$ crystallites were gradually reduced, generating numerous Ag hexagonal plate seeds while releasing $\mathrm{Cl}^{-}$ions. The formation of $\mathrm{Ag}$ hexagonal plates could be explained by preferential adsorption of $\mathrm{Cl}^{-}$on the $\{111\}$ basal surfaces of fcc $\mathrm{Ag}^{18}$, and the stacking faults on the side surfaces parallel to $\{111\}$ surfaces $^{19,20}$. Subsequently, Ag atoms may directly deposit on the Ag hexagonal sides due to the edge defects and associated higher surface energy. For comparison, we have also immersed $\mathrm{Cl}^{-}$-free virgin $\mathrm{MAC}$ in $\left[\mathrm{Ag}\left(\mathrm{NH}_{3}\right)_{2}\right] \mathrm{NO}_{3}$ solution and found that the product shape was quite irregular (Supplementary Fig. S2 online). Therefore, it seems that crystalline seeds are indispensible for the growth of wellcrystallized nanoparticles in our reaction system.

With the growing process continued, many silver nanobelts and large nanosheets appeared in ca. $30 \mathrm{~min}$ (Fig. 5c). At the same time, it became quite difficult to find silver hexagonal plates on the MAC surface. Therefore, it is suggested that the hexagonal plates obtained at earlier stages still grow along the $\{100\}$ hexagonal plate sides, either on all six sides to form nanosheets, or only on two neighboring sides and grow into nanobelts. Notably, some irregular Ag nanosheets with short nanobelt tapes and/or indentations were frequently found in this sample (Supplementary Fig. S3 online). The reason for the formation of such irregular products remains unclear. It is reminiscent of a study where similar silver structures were also found when using $\mathrm{NH}_{3} \cdot \mathrm{H}_{2} \mathrm{O}$ to tune the $\mathrm{pH}$ value ${ }^{18}$, inferring that $\mathrm{NH}_{3} \cdot \mathrm{H}_{2} \mathrm{O}$ may play a role in etching the silver nanosheets. Such nanosheets mostly disappeared in the later growing process, and silver nanobelts became the only dominant products after $12 \mathrm{hr}$ (Fig. 5d).

\section{Discussion}

It is of paramount importance to know what caused the reduction of $\mathrm{Ag}^{+}$. In the preparation of silver nanostructures, various reducing agents have been employed, such as polyols ${ }^{21}$, citrate ${ }^{22}$, ascorbic $\operatorname{acid}^{23}$ etc. Other reducing/transformation protocols include more reactive metals (termed as galvanic replacement) ${ }^{24}$, colloidal reflux ${ }^{10}$, light mediation ${ }^{25}$ and electrochemical reduction ${ }^{26}$. However, in our work, all these reducing forces have been avoided. The silver growth simply proceeded on the surface of an MAC immersed in a freshlyprepared $\left[\mathrm{Ag}\left(\mathrm{NH}_{3}\right)_{2}\right] \mathrm{NO}_{3}$ solution. The MAC had been vigorously ultrasonicated in DI water to remove physically-adsorbed species. And the experimental setup was shunned off common laboratory light. Therefore, the reduction could only be exerted by chemically (probably covalently) bound functional groups on the porous MAC surface $e^{27,28}$

To identify the reductive groups in our reaction system, FTIR was performed on virgin, used, and post-treated (by ammonium) MAC samples. These samples were ultrasonicated in fresh water, dried, ground into powders, mixed with $\mathrm{KBr}$ and pressed into small discs prior to FTIR characterization (more experimental details are given in the Methods). Unfortunately, it was not always successful in catching the spectral difference between the virgin and used MAC samples (possible reasons will be discussed below). Often all spectra look quite similar. Figure 6 displays a set of FTIR spectra through which the chemical reaction on the activated carbon may be inferred. In virgin MAC (curve a), the most intense peak at $3429 \mathrm{~cm}^{-1}$ can be assigned to alcohol or phenol-OH stretching. The two peaks at 2858, $2960 \mathrm{~cm}^{-1}$ may be attributed to symmetric, asymmetric $-\mathrm{CH}_{2}$ stretching respectively. The peaks at $1633 \mathrm{~cm}^{-1}$ could be ascribed to $\mathrm{C}=\mathrm{C}$ or $\mathrm{C}=\mathrm{O}$ stretching. After the growth of silver (curve $\mathrm{c}$ ), there is significant alleviation of $-\mathrm{OH}$ stretching $\left(3429 \mathrm{~cm}^{-1}\right)$ intensity, especially when compared to $-\mathrm{CH}_{2}$ stretching (2858 and $2960 \mathrm{~cm}^{-1}$ ). The peak intensity at $1633 \mathrm{~cm}^{-1}$ is also fairly reduced. This suggested that $\mathrm{OH}$ groups were involved in the chemical reaction. At the same time, two new peaks appeared in the used activated carbon (curve c). According to the literatures on the characterization of chemically modified porous carbon ${ }^{29}$, the peak at $1732 \mathrm{~cm}^{-1}$ can be ascribed to carboxylic $\mathrm{O}-\mathrm{C}=\mathrm{O}$ asymmetric stretching, and the broad shoulder peak at $3174 \mathrm{~cm}^{-1}$ is attributable to $-\mathrm{OH}$ stretching in $\mathrm{COOH}$ groups as a result of $\mathrm{H}$-bonding. Therefore, the FTIR results suggested that there was an oxidative transformation from hydroxyl and/or carbonyl groups to carboxylic groups in the process of silver growth. Given the existence of $\mathrm{O}_{2}$ in the atmosphere and in the pores of the microporous carbon, the hydroxyl groups may be
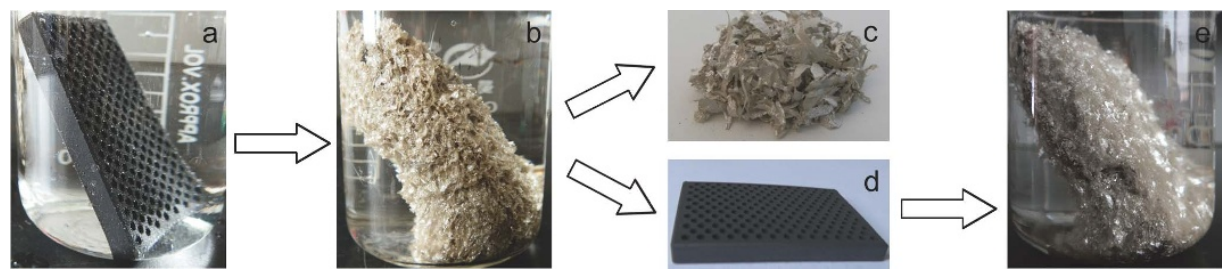

Figure $4 \mid$ Photograph of Ag samples obtained on virgin and post-treated monolithic activated carbon (MAC). (a) virgin MAC just being put in $\left[\mathrm{Ag}\left(\mathrm{NH}_{3}\right)_{2}\right] \mathrm{NO}_{3}$ solution (100 mM,50 ml); (b) Ag grown on virgin MAC after $24 \mathrm{hr}$; (c) Ag product taken from (b) and dried; (d) The same MAC after taking away the silver product. The MAC was ultrasonicated in ammonium solution (wt 5\%) for about 1 hour, flushed with plenty of deionized water, and dried; (e) Ag grown on post-treated MAC (shown in d) after the MAC being put in $\left[\mathrm{Ag}\left(\mathrm{NH}_{3}\right)_{2}\right] \mathrm{NO}_{3}$ solution (100 mM,50 ml) for $24 \mathrm{hr}$. 

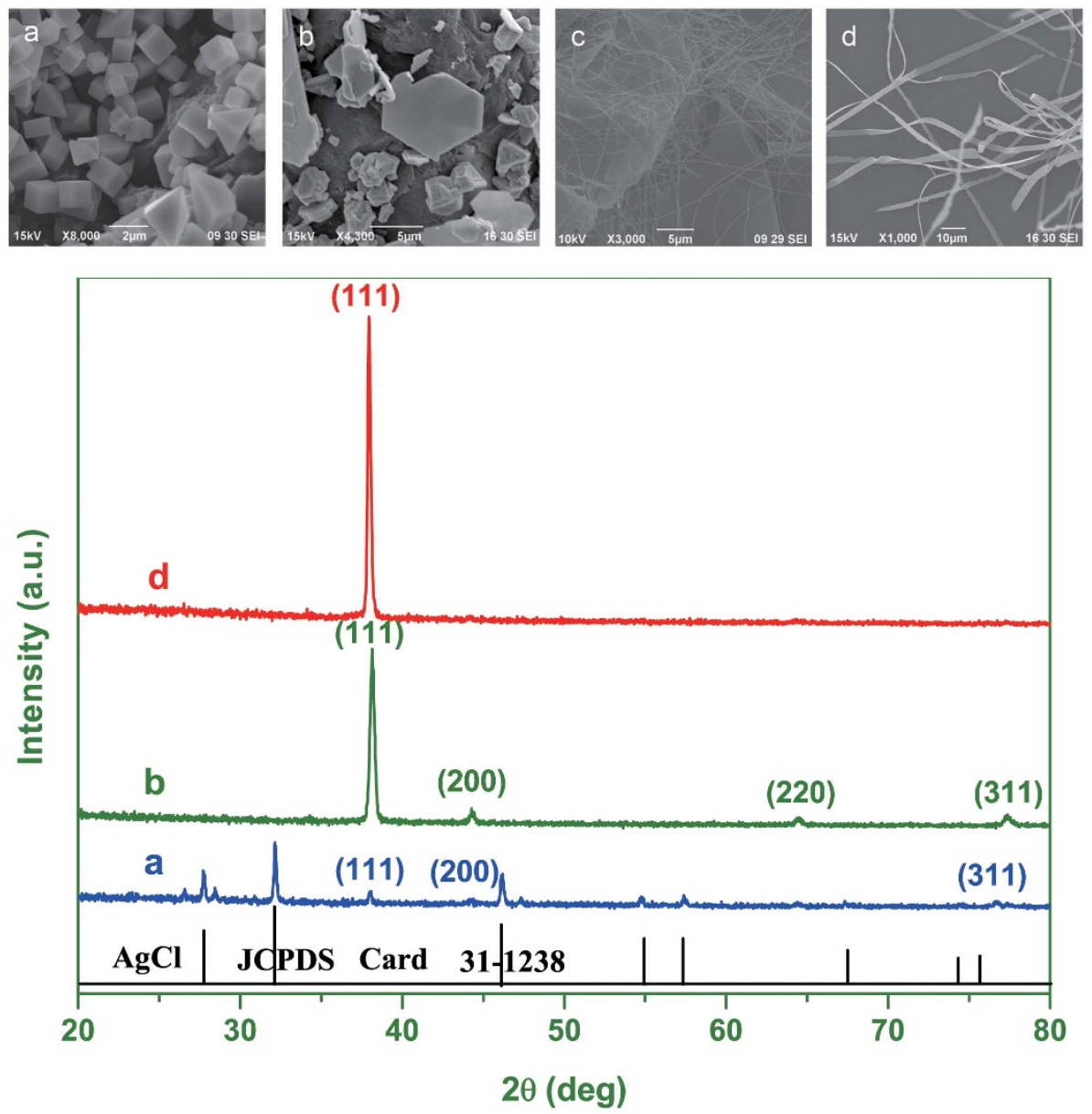

Figure 5 SEM images and XRD spectra showing the growth process of Ag nanobelts on monolithic activated carbon (MAC). The samples were obtained after immersing monolithic activated carbon (MAC) in $\left[\mathrm{Ag}\left(\mathrm{NH}_{3}\right)_{2}\right] \mathrm{NO}_{3}$ solution $(5 \mathrm{mM}, 30 \mathrm{ml}$ ) for (a) $1 \mathrm{~min}$; (b) $10 \mathrm{~min}$; (c) $30 \mathrm{~min}$; (d) $12 \mathrm{hr}$. SEM images for (a), (b) and (c) were directly taken on MAC surface, while SEM image (d) was obtained from detached Ag sample. XRD samples (a) and (b) were prepared by grinding MAC into powder, while XRD sample (d) was detached Ag product.

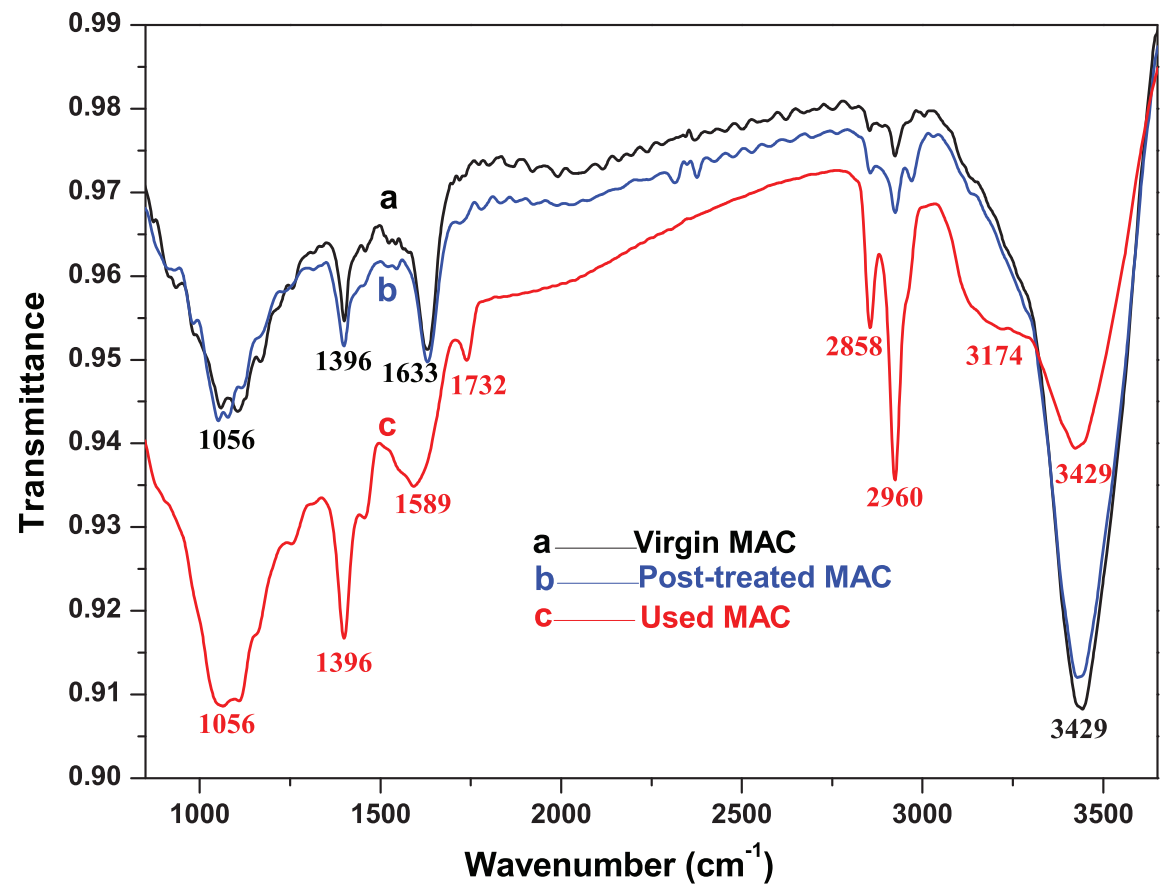

Figure 6 FTIR spectra of monolithic activated carbon (MAC) for (a) virgin MAC; (b) post-treated MAC; (c) used MAC. For (b), the treatment was performed by ultrosonicating MAC in ammonium solution (wt 5\%) for ca. 1 hour, flushed with plenty of deionized water, and dried. 
first oxidized to aldehyde by $\mathrm{O}_{2}$, and then to carboxylic acid by galvanic reaction, in agreement with the mechanism proposed by Xia et al. for their polyol approach ${ }^{30}$. The rich functional groups contained in our activated carbon can be associated with its biological source. After the detachment of Ag, it can be seen that $\mathrm{OH}$ groups were regenerated by ammonium ultrasonication and drying (curve b), which may explain why we obtained silver crystals with similar amount after the treatment (Fig. 4).

In our previous work ${ }^{13}$, we have proposed a galvanic-cell mechanism for the preparation of silver nanodendrites on MAC (Fig. 1). Considering the large BET surface of MAC, silver nanocrystals can be produced in quite high yield, which was not clearly expressed in that work. For example, for the MAC used in this work, it is estimated that $0.35 \mathrm{~g}$ silver nanocrystal can be produced on $1 \mathrm{~g}$ MAC, provided that all the reductive groups on the inner pores can be oxidized through galvanic-cell mechanism (see Supplementary Information for estimation method). If only the reductive groups on the outer surface can be oxidized for the preparation of silver, then its yield would not exceed $1 \times 10^{-6} \mathrm{~g}$. In this work, we have obtained ca. $0.11 \mathrm{~g}$ silver on $1 \mathrm{~g}$ MAC in one batch, implying ca. $31.5 \%$ available reductive groups in the inner pores have been electrochemically oxidized. However, the reacted functional groups only constitute 9.7\% of all oxygen-containing functional groups, which is difficult to tell by FTIR in each experimental trial.

To understand the electrochemical behavior of the MAC, cyclic voltammorgram (Fig. 7) was conducted in a three-electrode configuration in a $50-\mathrm{ml}$ beaker where $0.1 \mathrm{M} \mathrm{NaNO}_{3}$ was used as the electrolyte. MAC was ground into fine powders, mixed with ethanol, and loaded onto the surface of a glassy carbon working electrode. (The details of the experimental setup was given in the Methods) Two types of MAC used in this work were characterized. Both had one anodic (at $\sim 0.22 \mathrm{~V}$ ) and two cathodic peaks (at $-0.17 \mathrm{~V}$ and $-0.08 \mathrm{~V})$. The intensity of these three peaks attenuated simultaneously with the experiments going on, indicating that the peak at $0.22 \mathrm{~V}$ is the anodic counterpart to either of the two cathodic peaks. Consider the IR results discussed above, the anodic peak at $0.22 \mathrm{~V}$ was tentatively assigned to $\mathrm{R}-\mathrm{CHO}+\mathrm{H}_{2} \mathrm{O} \rightarrow \mathrm{R}-\mathrm{COOH}+2 \mathrm{H}^{+}+$ $2 \mathrm{e}$, while two cathodic peaks at $-0.17 \mathrm{~V},-0.08 \mathrm{~V}$ to $\mathrm{R}-\mathrm{CHO}+2 \mathrm{H}^{+}$ $+2 \mathrm{e} \rightarrow \mathrm{R}-\mathrm{CH}_{2} \mathrm{OH}, \mathrm{R}-\mathrm{COOH}+2 \mathrm{H}^{+}+2 \mathrm{e} \rightarrow \mathrm{R}-\mathrm{CHO}+\mathrm{H}_{2} \mathrm{O}$ respectively. However, more investigation is still required for the verification of this assignment. Anyway, our CV results did confirm that functional groups on MAC can be electrochemically converted in reducing $\mathrm{Ag}^{+}$for the growth of $\mathrm{Ag}$ nanostructures.
For the galvanic-cell mechanism (Fig. 1), some factors can influence the silver growth process, such as the cell potential, the density of reductive groups, the mobility of charge carriers (ions and electrons), the surface and pore structure of MAC, some accelerating/ retarding species adsorbed on MAC or contained in the solution, and the solution temperature etc. Among them, the cell potential is perhaps the key influential factor, which in turn is influenced by the substrate type (the anode), the identity and concentration of the silver precursor (the cathode). For example, the galvanic-displacement growth of $\mathrm{Ag}$ on $\mathrm{Al}$ or $\mathrm{Zn}$ substrates tends to produce dendritic or flower-like products, since elemental $\mathrm{Al}$ and $\mathrm{Zn}$ are much more reactive than $\mathrm{Ag}$, which lead to high cell potentials ${ }^{31-33}$. On Cu microparticles $^{14}$, the particle size, the identity and concentration of silver precursor can all influence the product morphology. Large $\mathrm{Cu}$ particle size $(10 \mu \mathrm{m})$ and high concentration of $\mathrm{AgNO}_{3}$ mainly resulted in dendritic products. On smaller $\mathrm{Cu}$ particles $(1 \mu \mathrm{m})$, silver nanobelts, nanodiscs were obtained in $\mathrm{AgNO}_{3}$ solution at higher $(10 \mathrm{mM}$, $\Delta \mathrm{E}=0.35 \mathrm{~V})$, lower $(1 \mathrm{mM}, \Delta \mathrm{E}=0.29 \mathrm{~V})$ concentrations, respectively. Replacing $\mathrm{AgNO}_{3}$ by $\left[\mathrm{Ag}\left(\mathrm{S}_{2} \mathrm{O}_{3}\right)\right]^{-}$complex $(5 \mathrm{mM}, \Delta \mathrm{E}=$ $0.18 \mathrm{~V}$ ) led to uniform deposition of $\mathrm{Ag}$ nanoshells on $\mathrm{Cu}$. It is reasoned that lower cell potential resulted in lower driving force and more thermodynamically-controlled reaction, and more uniform growth of the crystals. In the current work, instead of $\mathrm{AgNO}_{3}$ used in our previous work ${ }^{13}$, a silver complex $\left[\mathrm{Ag}\left(\mathrm{NH}_{3}\right)_{2}\right]^{+}$was used as the silver precursor. In addition, the inherent $\mathrm{Cl}^{-}$in MAC produced $\mathrm{AgCl}$ cubes in the initial reaction step (Fig. 4a). Compare the standard reduction potential of $\mathrm{Ag}^{+}\left|\mathrm{Ag}(0.80 \mathrm{~V}),\left[\mathrm{Ag}\left(\mathrm{NH}_{3}\right)_{2}\right]^{+}\right| \mathrm{Ag}$ $(0.38 \mathrm{~V})$ and $\mathrm{AgCl} \mid \mathrm{Ag}(0.22 \mathrm{~V})$, we could see there is significant decrease in the reduction potential. Moreover, the high solubility of $\left[\mathrm{Ag}\left(\mathrm{NH}_{3}\right)_{2}\right]^{+}$and the complexation structure may provide a good buffer solution of $\mathrm{Ag}^{+}$near the $\mathrm{Ag}$ deposition region. Our adjustment made it possible for the quasi-equilibrium growth of well-crystallized silver nanostructures, avoiding the growth of dendritic crystals, which are normally obtained in an unstable reaction condition where the diffusion of the solute ions is the limiting factor ${ }^{14}$.

At the quasi-equilibrium growth condition, by varying the precursor concentration, the cell potential can be finely tuned. As derived from Nernst Equation, the decrease of the precursor concentration by one order will result in the decrease of cell potential by ca. $0.06 \mathrm{~V}$, which had been large enough for producing silver crystals with different morphology, as discussed above ${ }^{14}$. In this work, by setting the $\left[\mathrm{Ag}\left(\mathrm{NH}_{3}\right)_{2}\right] \mathrm{NO}_{3}$ concentration at $100 \mathrm{mM}, 5 \mathrm{mM}$, $0.1 \mathrm{mM}$, silver crystals in the form of nanoflower, nanobelt,

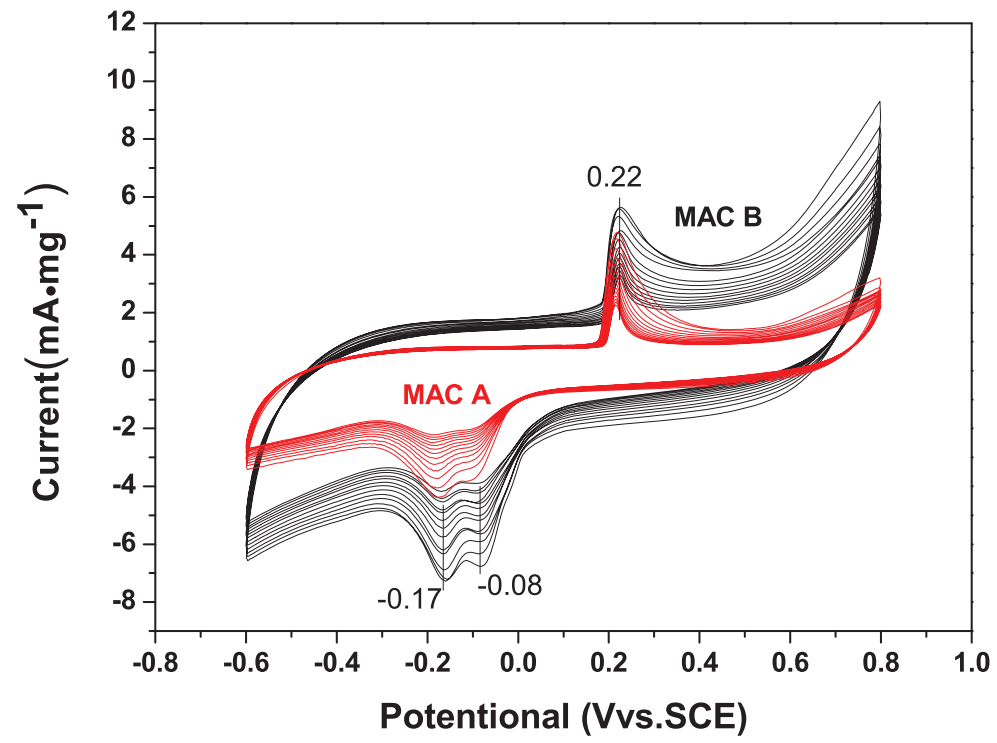

Figure $7 \mid$ Cyclic voltammograms of two monolithic activated carbon (MAC). Scan rate $=0.1 \mathrm{~V} / \mathrm{s}$ 


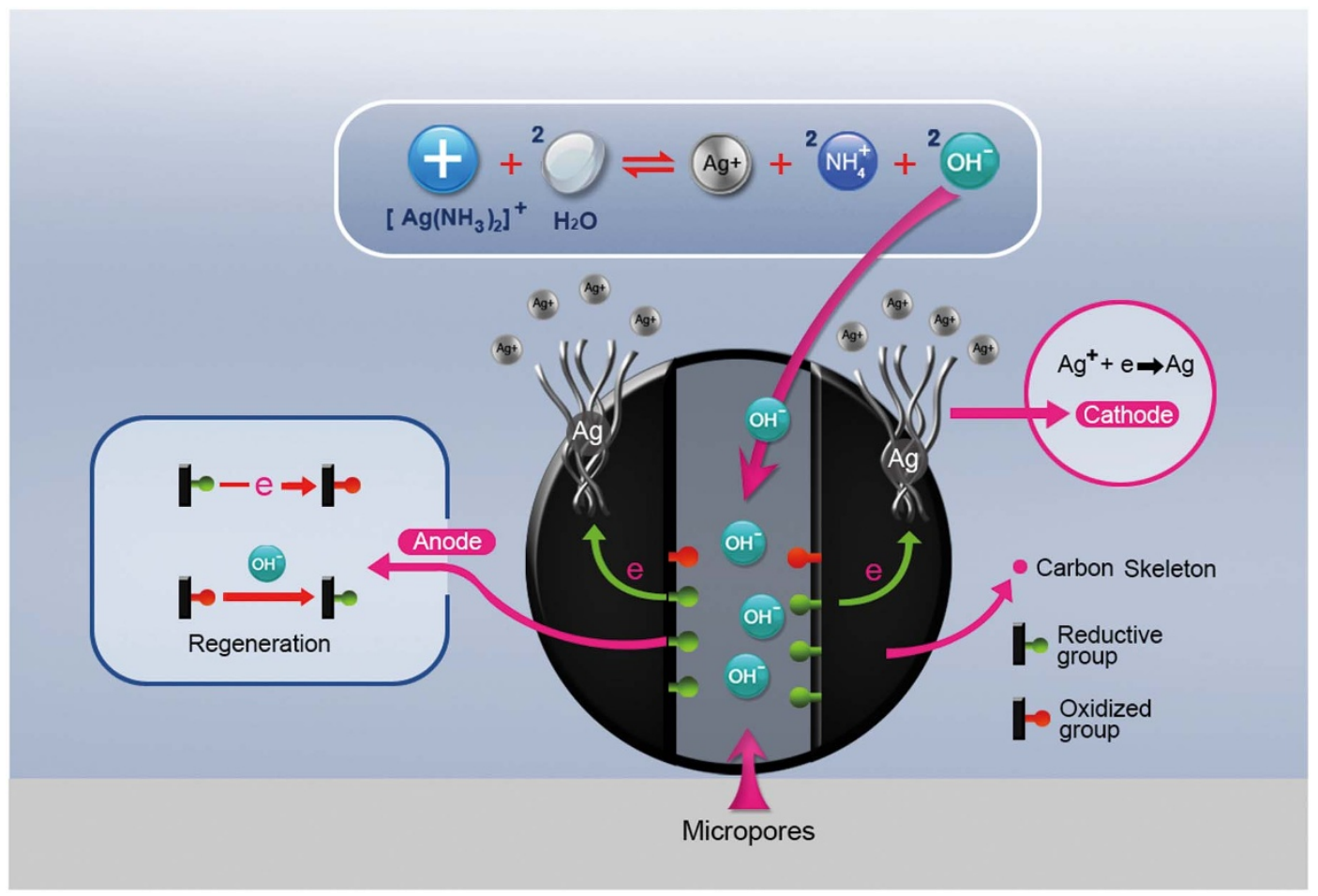

Figure $8 \mid$ A schematic of the galvanic-cell mechanism for the growth of silver nanobelts by immersing microporous monolithic activated carbon $(\mathrm{MAC})$ in $\left[\mathrm{Ag}\left(\mathrm{NH}_{3}\right)_{2}\right] \mathrm{NO}_{3}$ solution.

nanoplates were obtained respectively (Fig. 3). The preparation of flower-like silver product at $100 \mathrm{mM}$ may be explained by the aggregation of silver flakes due to the low $\mathrm{Cl}^{-} / \mathrm{Ag}$ ratio, where $\mathrm{Cl}^{-}$ can be regarded as the capping agent on $\{111\}$ surfaces $^{15}$. In addition, the morphological change from nanobelt to nanoplate with reduced $\left[\mathrm{Ag}\left(\mathrm{NH}_{3}\right)_{2}\right]^{+}$concentration is in agreement with that on $\mathrm{Cu}$ microparticles, where higher cell potential leads to anisotropic 1-D growth, and lower cell potential leads to more thermodynamic control and the formation of 2-D $\mathrm{Ag}^{14,34}$.

Finally, the effect of silver precursor on the solution and MAC can be considered. According to the anode reaction $\mathrm{R}-\mathrm{CHO}+\mathrm{H}_{2} \mathrm{O} \rightarrow$ $\mathrm{R}-\mathrm{COOH}+2 \mathrm{H}^{+}+2 \mathrm{e}$ mentioned above, the acidity of the solution would be improved if there were no other influential factors. On the other hand (Fig. 8), the hydrolysis of $\left[\mathrm{Ag}\left(\mathrm{NH}_{3}\right)_{2}\right]^{+}$precursor, $\left[\mathrm{Ag}\left(\mathrm{NH}_{3}\right)_{2}\right]^{+}+2 \mathrm{H}_{2} \mathrm{O} \rightarrow \mathrm{Ag}^{+}+2 \mathrm{NH}_{4}{ }^{+}+2 \mathrm{OH}^{-}$, can produce $\mathrm{OH}^{-}$ions, which may somewhat neutralize the acidity with the progress of galvanic deposition. Furthermore, it has been reported ${ }^{35}$ that alkaline treatment of activated carbon can regenerate $-\mathrm{OH}$ functional groups on the activated carbon surface. In this way, the declining of reductive groups can be hindered, keeping the cell potential at a relatively stable value during silver growth. Hence, a self-compensatory growth of $\mathrm{Ag}$ nanocrystals can be realized at a quasi-equilibrium condition. We have also found that pure $\mathrm{Ag}_{2} \mathrm{O}$ is a very good precursor for the growth of silver nanobelts on MAC in a high yield, further suggesting the beneficial effect of $\mathrm{OH}^{-}$(generated from $\mathrm{Ag}_{2} \mathrm{O}$ hydrolysis) in the formation of stable reaction environment.

In conclusion, we have developed a method to producing silver nanocrystals on monolithic activated carbon (MAC) in a very high yield, and realized the tuning of morphology by changing precursor concentrations. The silver growing process is investigated in detail, and the proposed galvanic-cell mechanism is further studied by analyzing the surface functional groups and the electrochemical behavior of the activated carbon electrode. It is argued that the lowering of the cell potential by using $\left[\mathrm{Ag}\left(\mathrm{NH}_{3}\right)_{2}\right]^{+}$complex precursor, the $\mathrm{AgCl}$ crystalline seed-initiation, and the regeneration of the reductive groups facilitate the self-compensatory growth of Ag nano- belts. As the silver nanocrystals grew out of environmental-friendly MAC template in aqueous solution without any organic reductants or capping agents ${ }^{36}$, this process is quite like planting seeds and producing harvests abundantly in a field. It is anticipated that this work will pave the way for customizing the production of various kinds of noble metal nanocrystals in a green mode and at an industrial scale.

\section{Methods}

Chemical and materials. Monolithic Activated Carbon (MAC) samples, derived from corn straw, were provided by Qufu Tembton Technology Co. Ltd. Shandong, China. Their structural and compositional information is presented in Supplementary Table S1 and Table S2 online. $\mathrm{AgNO}_{3}$, ammonia water (25 28 wt\%), anhydrous ethanol were purchased from Shanghai Chemical Reagent Co. Ltd. All chemicals were of analytical grade and used without further purification.

$\left[\mathrm{Ag}\left(\mathrm{NH}_{3}\right)_{2}\right] \mathrm{NO}_{3}$ solution was prepared by continuously dropping ammonia water into $1 \mathrm{M} \mathrm{AgNO}_{3}$ until the dissolution of the brown $\mathrm{Ag}_{2} \mathrm{O}$ precipitate.

$\left[\mathrm{Ag}\left(\mathrm{NH}_{3}\right)_{2}\right] \mathrm{NO}_{3}$ solutions at lower concentrations were obtained by dilution with deionized (DI) water accordingly. DI water was generated from TTL-30C Ultrapure Water Generator, with electrical resistivity of $18.2 \mathrm{M} \Omega \cdot \mathrm{cm}$.

Preparation of silver nanocrystals. MAC was cut into small pieces and ultrasonicated in DI water to remove contaminants. The silver nanocrystals were prepared by immersing MAC into freshly-prepared $\left[\mathrm{Ag}\left(\mathrm{NH}_{3}\right)_{2}\right] \mathrm{NO}_{3}$ solution at different concentrations in the dark to avoid silver photoreduction. All experiments were carried out at room temperature $\left(\mathrm{ca} .25^{\circ} \mathrm{C}\right)$. The Ag products were detached from MAC with tweezers. For the reactivation of MAC, the used MAC was ultrasonicated in ammonium solution ( $5 \mathrm{wt} \%$ ) for ca. $1 \mathrm{hr}$, washed with DI water and dried at $60^{\circ} \mathrm{C}$ for $2 \mathrm{hr}$.

Characterization. Photograph. All photographs in this work were taken with a digital camera (OLYMPUS SZ-10).

SEM. Scanning electron microscope (SEM) experiments were performed on JEOL JSM-6390LV instrument. The images were taken in secondary electron mode, with an accelerating voltage of $15 \mathrm{kV}$, working distance of ca. $7 \mathrm{~mm}$. Samples were mounted on $\mathrm{Al}$ stages with conductive carbon tapes.

TEM. Transmission electron microscope (TEM) and selected-area electron diffraction (SAED) images were collected in a Philips CM10 instrument at an accelerating voltage of $160 \mathrm{kV}$. TEM samples were prepared by sonicating Ag product in 
anhydrous ethanol for 5 min,taking some suspension droplets and drying in a carbon-film coated copper grid.

$X R D$. The powder X-ray diffraction (XRD) pattern was recorded by using a Bruker AXS D8 X-ray diffractometer with $\mathrm{Cu} K \alpha$ radiation $(\lambda=1.5418 \AA)$. The measurement parameters were set at $20^{\circ} \sim 80^{\circ} 2 \theta$ range, $0.02^{\circ}$ sampling frequency, $2^{\circ} / \mathrm{min}$ scanning speed, $30 \mathrm{kV}$ tube voltage and $40 \mathrm{~mA}$ tube current, respectively.

FTIR. Fourier Transform Infrared (FTIR) spectra were collected by using a Bruker Tensor 27 instrument within the range of $400-4000 \mathrm{~cm}^{-1} .16$ scans and $4-\mathrm{cm}^{-1}$ resolutions were applied. For specimen preparation, MAC samples were dried, ground in an agate mortar, thoroughly mixed with $\mathrm{KBr}$ at an approximate ratio of $1 / 100$ and pressed into small discs at 10 tons for $5 \mathrm{~min}$.

$\mathrm{CV}$. Cyclic voltammetric (CV) measurements were performed by using a $\mathrm{CHI} 660 \mathrm{~d}$ electrochemical analyzer (CH Instruments, Shanghai Chenghua Co.) in a conventional three-electrode configuration. A Pt plate auxiliary electrode, a saturated calomel reference electrode (SCE), and $0.1 \mathrm{M} \mathrm{NaNO}_{3}$ electrolyte solution were used. For the preparation of working electrode, MAC was ground into powder, and $4 \mathrm{mg}$ of the powder and $1.6 \mathrm{~mL}$ anhydrous ethyl alcohol were thoroughly mixed by sonication for $1 \mathrm{hr}$ to generate an evenly distributed suspension. Then $4 \mu \mathrm{L}$ of the resulting suspension was laid on the surface of the pre-cleared glassy carbon electrode $(3 \mathrm{~mm}$ in diameter, $0.07 \mathrm{~cm}^{2}$ ). After drying at room temperature, $3 \mu \mathrm{L}$ Nafion (5.0 $\mathrm{wt} \%$ ) solution was covered on the surface of the working electrode and allowed to dry again. The as-prepared working electrode had a specific MAC loading of $\mathrm{ca} .0 .14 \mathrm{mg} / \mathrm{cm}^{2}$. All the electrochemical measurements were carried out at $30 \pm 1{ }^{\circ} \mathrm{C}$.

$B E T$. To determine the surface areas of MAC, the $\mathrm{N}_{2}$ adsorption-desorption isotherms were measured with an accelerated surface area and porosimetry system (ASAP Tristar, Micromeritics). A small piece of ca. $0.25 \mathrm{~g} \mathrm{MAC} \mathrm{was} \mathrm{used} \mathrm{as} \mathrm{the}$ sample. Prior to the measurements, the samples were dried at $100^{\circ} \mathrm{C}$ for 2 hours, and then outgassed at $623 \mathrm{~K}$, under $<6.67 \times 10^{-2} \mathrm{~Pa}$ pressure, for at least $4 \mathrm{~h}$. The nitrogen adsorption-desorption data were recorded at a liquid nitrogen temperature of $77 \mathrm{~K}$. The nitrogen adsorption isotherm was measured over a relative pressure $\left(\mathrm{p} / \mathrm{p}_{0}\right)$ range, from approximately 0.05 to 1 . The BET surface area was calculated using the BET equation from the selected $\mathrm{N}_{2}$ adsorption data, within a range of relative pressure, $\mathrm{p} / \mathrm{p}_{0}$, from 0.1 to 0.25 . Barrett-Joyner-Halenda (BJH) method was applied to obtain the pore size distribution in the mesopore range, and t-plot method to that in micropore range $(<17 \AA)$.

XPS. X-ray photoelectron spectroscope (Thermo Scientific ESCALAB 250) was applied to quantify elemental composition (except $\mathrm{H}$ ). The XPS spectra were obtained using a monochromated $\mathrm{Al} \mathrm{K \alpha}$ radiation $(1486.6 \mathrm{eV}$ ), which was operated at $15 \mathrm{kV}$ and $14 \mathrm{~mA}$. The pass energy for wide scans was set at $160 \mathrm{eV}$, while the narrow scans at $40 \mathrm{eV}$. The $\mathrm{C}(1 \mathrm{~s})$ electron binding energy peak was set at $284.6 \mathrm{eV}$ for calibration purposes.

1. Zhang, H., Jin, M., Xiong, Y., Lim, B. \& Xia, Y. Shape-controlled synthesis of Pd nanocrystals and their catalytic applications. Acc. Chem. Res. (2012). DOI: 10.1021/ar300209w.

2. Tao, A., Sinsermsuksakul, P. \& Yang, P. Tunable plasmonic lattices of silver nanocrystals. Nature Nanotech. 2, 435-440 (2007).

3. Cao, Y., Jin, R. \& Mirkin, C. Nanoparticles with raman spectroscopic fingerprints for DNA and RNA detection. Science 297, 1536-1540 (2002).

4. Guo, S. \& Wang, E. Noble metal nanomaterials: controllable synthesis and application in fuel cells and analytical sensors. Nano Today 6, 240-264 (2011).

5. Im, S. H., Lee, Y., Wiley, B. \& Xia, Y. Large-scale synthesis of silver nanocubes: the role of $\mathrm{HCl}$ in promoting cube perfection and monodispersity. Angew. Chem. 117, 2192-2195 (2005).

6. Skrabalak, S. E., Au, L., Li, X. \& Xia, Y. Facile synthesis of Ag nanocubes and Au nanocages. Nature Protocols 2, 2182-2190 (2007)

7. Baše, T. et al. Gold micrometer crystals modified with carboranethiol derivatives. J. Phys. Chem. C 112, 14446-14455 (2008).

8. Huo, Z., Tsung, C., Huang, W., Zhang, X. \& Yang, P. Sub-two nanometer single crystal Au nanowires. Nano Lett. 8, 2041-2044 (2008).

9. Chen, Y., Somsen, C. \& Hassel, A. Fabrication of single crystalline gold nanobelts J. Mater. Chem. 19, 924-927 (2009).

10. Sun, Y., Mayers, B. \& Xia, Y. Transformation of silver nanospheres into nanobelts and triangular nanoplates through a thermal process. Nano Lett. 3 675-679 (2003).

11. Rycenga, M. et al. Controlling the synthesis and assembly of silver nanostructures for plasmonic applications. Chem. Rev. 111, 3669-3712 (2011).

12. Liu, B., Luo, W. \& Zhao, X. A facile synthesis of ordered ultralong silver nanobelts. Materials Research Bulletin 44, 682-687 (2009).

13. Wang, F. et al. Tunable growth of nanodendritic silver by galvanic-cell mechanism on formed activated carbon. Chem. Commun. 46, 3782-3784 (2010).

14. Liu, R. \& Sen, A. Unified Synthetic Approach to Silver Nanostructures by Galvanic Displacement Reaction on Copper: From Nanobelts to Nanoshells. Chem. Mater. 24, 48-54 (2012).
15. Yang, J., Qi, L., Zhang, D., Ma, J. \& Cheng, H. Dextran-controlled crystallization of silver microcrystals with novel morphologies. Cryst. Growth Des. 4, 1371-1375 (2004).

16. Chiu, C., Choi,Y. \& Luo, T. M. Formation of AgCl cubic crystals induced by shrinkage of Sol-Gel silica film. Cryst. Growth Des. 12, 4727-4732 (2012).

17. Zeng, J., Roberts, S. \& Xia, Y. Nanocrystal-based time-temperature indicators. Chem. Eur. J. 16, 12559-12563 (2010).

18. Chen, H., Simon, F. \& Eychmuller, A. Large-scale synthesis of micrometer-sized silver nanosheets. J. Phys. Chem. C 114, 4495-4501 (2010)

19. Millstone, J. E., Hurst, S. J., Metraux, G. S., Cutler, J. I. \& Mirkin, C. A. Colloidal gold and silver triangular nanoprisms. Small 5, 646-664 (2009).

20. Wang, Z. L. Transmission electron microscopy of shape-controlled nanocrystals and their assemblies. J. Phys. Chem. B 104, 1153-1175 (2000).

21. Tao, A., Sinsermsuksakul, P. \& Yang, P. Polyhedral silver nanocrystals with distinct scattering signatures. Angew. Chem. Int. Ed. 45, 4597-4601 (2006).

22. Caswell, K. K., Bender, C. M. \& Murphy, C. J. Seedless, surfactantless wet chemical synthesis of silver nanowires. Nano Lett. 3, 3667-3669 (2003).

23. Bai, J., Qin, Y., Jiang, C. \& Qi, L. Polymer-controlled synthesis of silver nanobelts and hierarchical nanocolumns. Chem. Mater. 19, 3367-3369 (2007).

24. Aizawa, M., Cooper, A. M., Malac, M. \& Buriak, J. M. Silver nano-inukshuks on germanium. Nano Lett. 5, 815-819 (2005).

25. Jin, R. et al. Controlling anisotropic nanoparticle growth through plasmon excitation. Nature 425, 487-490 (2003).

26. Liu, L., Yoo, S., Lee, S. A. \& Park, S. Electrochemical growth of silver nanobelts in cylindrical alumina nanochannels. Cryst. Growth Des. 11, 3731-3734 (2011).

27. Sun, X. \& Li, Y. Colloidal carbon spheres and their core/shell structures with noble-metal nanoparticles. Angew. Chem. 116, 607-611 (2004).

28. Biniak, S., Pakula, M. \& Swiatkowski, A. Infuence of surface chemical structure of activated carbon on its electrochemical behaviour in the presence of silver. J. Appl. Electrochem. 29, 481-487 (1999).

29. Shen, W., Li, Z. \& Liu, Y. Surface chemical functional groups modification of porous carbon. Recent Patents on Chemical Engineering 1, 27-40 (2008).

30. Skrabalak, S. E., Wiley, B. J., Kim, M., Formo, E. \& Xia, Y. On the polyol synthesis of silver nanostructures-glycolaldehyde as a reducing agent. Nano Lett. 8 2077-2081 (2008).

31. Gutes, A., Carraro, C. \& Maboudian, R. Silver dendrites from galvanic displacement on commercial Aluminum foil as an effective SERS substrate. J. Am. Chem. Soc. 132, 1476-1477 (2010).

32. You, H., Ding, C., Song, X., Ding, B. \& Fang, J. In situ studies of different growth modes of silver crystals induced by the concentration field in an aqueous solution. Cryst. Eng. Comm. 13, 4491-4495 (2011).

33. Gutes, A., Carraro, C. \& Maboudian, R. Silver nanodesert rose as a substrate for surface-enhanced raman spectroscopy. ACS Appl. Mater. Interfaces 1, 2551-2555 (2009).

34. Yang, Z. et al. Plasmonic silver nanobelts via citrate reduction in the presence of $\mathrm{HCl}$ and their orientation-dependent scattering properties. J. Phys. Chem. Lett. 2, 1742-1746 (2011).

35. Song, X. et al. Surface activated carbon nanospheres for fast adsorption of silver ions from aqueous solutions. J. Hazard. Mater. 194, 162-168 (2011).

36. Sharma, V. K., Yngard, R. A. \& Lin, Y. Silver nanoparticles: green synthesis and their antimicrobial activities. Adv. Colloid Interface Sci. 145, 83-96 (2009).

\section{Acknowledgements}

We thank Mr. Yu Xiang, design director of Materials Industrial Engineering Research Center (MIE), School of Materials Science and Engineering, Shanghai Jiao Tong University for drawing schematic diagrams. We also thank Qufu Tembton Technology Co. Ltd., Shandong, China for offering monolithic activated carbon samples. Our study is financially supported by Shanghai Jiao Tong University-Wintop joint research center of Environmental Protection and Energy Materials (SWEE).

\section{Author contributions}

B.Z. developed and directed the project. H.Z. together with F.W. performed the experiments. F.Y. carried out the SEM, TEM and characterization. Y.N., B.Z. and H.Z. analyzed the data and wrote the paper. J.Z., X.H., T.F., Y.L., J.T., D.Z. and K.H. contributed to the interpretation of the results.

\section{Additional information}

Supplementary information accompanies this paper at http://www.nature.com/ scientificreports

Competing financial interests: The authors declare no competing financial interests.

License: This work is licensed under a Creative Commons

Attribution-NonCommercial-ShareALike 3.0 Unported License. To view a copy of this license, visit http://creativecommons.org/licenses/by-nc-sa/3.0/

How to cite this article: Zhao, H. et al. Green “planting” nanostructured single crystal silver. Sci. Rep. 3, 1511; DOI:10.1038/srep01511 (2013). 